\title{
Early detection of subclinical dysfunction of left ventricle in dialysis patients
}

\section{Slavica Mitrovska* \\ Public Health Organization: Skopje, Skopje, Macedonia}

RECEIVED:

April 7, 2015

ACCEPTED:

April 20, 2015

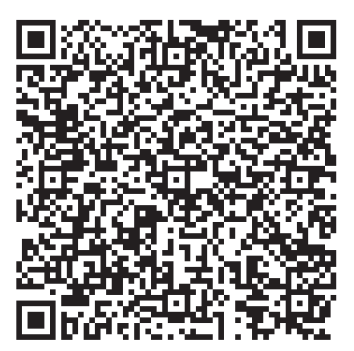

KEYWORDS: tissue Doppler imaging, pulsed-waved Doppler analysis, left ventricular diastolic dysfunction, hemodialysis.

CITATION: Cardiol Croat. 2015;10(3-4):64. | DOI: http://dx.doi.org/10.15836/ccar.2015.64

ORCID: Slavica Mitrovska, http://orcid.org/0000-0001-8552-269X

*ADDRESS FOR CORRESPONDENCE: Slavica Mitrovska, Public Health Organization, Department of Internal Medicine, Sole Stojcev br.1-2/8 1000, Skopje, Macedonia. Phone: +38971385267. E-mail: mitrovska2000@yahoo.com

||||||||||||||||||||||||||||||||||||||||||||||||||||||||||||||||||||||||||||||||||||||||||||||||||||||||||||||||||||||||||||||||

BACKGROUND: Continuous variations of volume and pressure in dialysis patients have an impact on left ventricular (LV) function. Pulsed-waved Doppler analysis records transmitral flow velocities and the volume changes affect its accuracy in the evaluation of cardiac function. Tissue Doppler imaging (TDI) quantifies mitral annular velocities and as a relatively load-independent method, more precisely reflects structural myocardial changes.

AIM: To assess the role of TDI in the early detection of subclinical dysfunction of the left ventricle in dialysis patients.

METHODS: Cross-sectional, single-center study that included 36 patients (24 men and 12 women, mean age 59+/-12 years), on regular hemodialysis (HD) program (mean HD vintage 48+/-71 months). All patients underwent transthoracic echocardiography (pulsed-wave Doppler and TDI) to assess diastolic function. To minimize the effect of fluid overload, analyses were performed 24 hours after HD session. We analyzed the diastolic parameters from both echo-techniques and their relations with traditional and uremia-related factors.

RESULTS: TDI identified significantly higher rate of diastolic dysfunction (DD) vs PW Doppler analyses ( $\mathrm{Z}=-4.26, \mathrm{p}$ $<0.00)$. TDI-derived diastolic velocities suggest a positive relationship with plasma levels of calcium $(r=0.65, p=0.03)$, calcium phosphate product $(r=0.63, p=0.03)$, LVMI $(r=0.53, p=0.03)$, and systolic blood pressure $(r=0.49, p=0.03)$, but negative correlation with hemoglobin $(r=-0.79, p=0.03)$ and hematocrit $(r=-0.74, p=0.03)$.

CONCLUSION: TVI is more sensitive method than PW Doppler for early identification of diastolic dysfunction and better identify dialysis patients at risk of development of heart failure. 